\title{
O DESIGN E A TECNOLOGIA NO BENEFICIAMENTO DO QUARTZO BRASILEIRO: FORMAS DE VALORIZAÇÃO
}

\author{
Andréia Salvan Pagnan \\ UEMG - Universidade do Estado de Minas Gerais \\ andreiasalvan@uol.com.br \\ Fernando Soares Lameiras \\ CDTN - Centro de Desenvolvimento de Tecnologia Nuclear \\ fsl@cdtn.br \\ Maria Regina Álvares Dias \\ UEMG - Universidade do Estado de Minas Gerais \\ regina.alvares@gmail.com
}

Resumo: o quartzo brasileiro não possui a devida valorização como matéria-prima brasileira, saindo em grande quantidade do país na sua forma bruta a baixos preços. O Brasil perde duas vezes quando também deixa de aplicá-lo nas peças de joias que poderiam divulgar tanto o material (gemas), quanto o design brasileiro. A coloração por meio de técnicas de beneficiamento como a irradiação e tratamento térmico possibilita agregar valor, minimizando a sua saída do país. Os resultados de coloração obtidos mostram o quanto a relação design e tecnologia pode valorizar o produto, tornando o setor joalheiro mais competitivo. A aplicação dos resultados de gemas coloridas às peças de joias pode ser vista nesta pesquisa com o objetivo de mostrar o papel do designer de joias como propagador de valor junto ao usuário de joias, que de acordo com Krucken (2009), é construído conjuntamente por indivíduos e empresas que integram seus conhecimentos e competências. Sendo assim, o consumidor se apresenta como parte ativa e fundamental na construção de valor.

Palavras-chave: Design, tecnologia, irradiação, aquecimento, quartzo.

\begin{abstract}
Brazilian raw material, leaving a large amount of the country in its raw form at low prices. Brazil loses twice when also fails to apply it in the jewelry pieces that could disclose both the material (gems), the Brazilian design. Staining by means of processing techniques such as irradiation and heat treatment makes it possible to add value while minimizing their exit from the country. Staining results shows how the relationship design and technology can enhance the product, making it the most competitive jewelry industry. The application of the results of colored gemstones to jewelry pieces can be seen in this study in order to show the role of jewelry designer and
\end{abstract}


propagator value with the jewelry user, which according to Krucken (2009), is built jointly by individuals and companies that integrate their knowledge and skills. Thus, the consumer is presented as active and important part in building value.

Keywords: Design, technology, radiation, heating, quartz.

\section{INTRODUÇÃO}

O design possui um papel fundamental na propagação da valorização da matéria-prima brasileira, e pode realização tal função tanto pela sua aplicação nas joias com identidade brasileira, quanto por meio de estratégias que capacitem as cooperativas de produtores. O beneficiamento é uma forma de agregar valor aos minerais extraídos do território brasileiro que saem do país na sua forma bruta a preços insignificantes. $\mathrm{O}$ uso da tecnologia para tratar gemas incolores ou de coloração fraca, de baixo valor comercial, é uma das formas de trazer competitividade ao setor joalheiro. Os resultados parciais de pesquisa de mestrado em design da Universidade $\mathrm{XX}$, com foco em técnicas de beneficiamento do quartzo brasileiro mostram as possibilidades de coloração resultante dos processos de irradiação e tratamento térmico. O citrino pode ser encontrado na natureza, embora grande parte das amostras comercializadas seja resultante de beneficiamento. Segundo Schmetzer (1989), citrinos podem resultar tanto de ametistas do Rio Grande do Sul e Pará, quanto de quartzos fumê submetidos ao tratamento térmico. A sua aplicação nas joias brasileiras pode ser vista tanto no setor comercial, quanto nas peças finalistas de concursos de joias promovidos pelas entidades brasileiras e institutos como IBGM ${ }^{1}$. As premiações nacionais e internacionais trazem visibilidade tanto à matéria-prima quanto ao design brasileiro que consegue mostrar sua identidade.

\section{DESENVOLVIMENTO}

A pouca valorização das pedras brasileiras como riqueza do solo é um problema no setor de joias, pois as mesmas são exportadas, em sua maioria, em estado bruto a baixo custo. São fatores determinantes desse fluxo o incentivo aos garimpeiros por parte das empresas exportadoras que visam à produção de quartzo para indústrias de alta tecnologia, e também a política tributária que não favorece o setor de gemas e joias. Sendo assim, a cadeia produtiva joalheira fica prejudicada, uma vez que vende a matéria-prima bruta extraída no Brasil com isenção de impostos a um preço irrisório, sendo que a mesma poderia ser beneficiada no próprio país e comercializada a preços melhores.

O design possui seu papel como agregador de valor à matéria-prima por meio de técnicas de beneficiamento para coloração de gemas. O beneficiamento como forma de agregar valor à matéria-prima é uma forma de minimizar o problema ambiental, uma vez que reduz o interesse pela venda da pedra bruta impedindo dessa forma a lavra predatória. A extração de pedras no Brasil acontece por meio de pequenas empresas, na sua maioria de forma rudimentar nas minas localizadas nos estados de Minas Gerais, Rio Grande do Sul, Bahia, Goiás, Pará e Tocantins, das quais

\footnotetext{
${ }^{1}$ Instituto Brasileiro de Gemas e Metais Preciosos
} 
saem grande quantidade e variedade de gemas. Aproximadamente $80 \%$, em volume da produção de gemas se destinam à exportação, tanto no estado bruto como em objeto de coleção e lapidadas.

No setor de gemas e joias, Favacho (2001), cita Minas Gerais como um estado que agrega pouco valor às suas gemas pelo fato de atuar, principalmente, como simples fornecedor para outros países. As gemas mineiras, quando exportadas em seu estado bruto, pouco contribuem para a economia. Assim a indústria de gemas e joias de Minas Gerais só poderá participar ativamente do mercado externo caso sejam criadas condições adequadas para o aumento de sua competitividade, congregando esforços para se beneficiarem internamente metais e gemas.

O beneficiamento como forma de agregar valor à matéria-prima é uma forma de minimizar o problema ambiental, uma vez que reduz o interesse pela venda da pedra bruta e com isso diminui a extração. As gemas brasileiras passam por beneficiamento como lapidação e coloração por irradiação, processos que aumentam seu preço de venda. O quartzo incolor pode ser citado como exemplo por ser abundante no solo brasileiro, estando o país entre os principais produtores mundiais.

O tratamento por irradiação ainda é desconhecido por parte de muitos dos atores da cadeia produtiva, principalmente garimpeiros que desconhecem a agregação de valor que o processo oferece às gemas. Ao propor novas formas de irradiação que irão gerar diferentes formas de coloração significa conduzir ações em nível sistêmico e estabelecer redes favoráveis ao desenvolvimento local. Segundo Favacho (2001) ao ser irradiado o quartzo agrega um valor de aproximadamente $400 \%$ sobre o valor original de uma gema que possuía uma cor fraca ou incolor.

Este artigo mostra resultados parciais de pesquisa de dissertação de mestrado com pesquisa em técnicas de beneficiamento do quartzo brasileiro, buscando a sua valorização como matéria-prima do território. Os resultados de coloração por irradiação e tratamento térmico são apresentados com ametista oriunda de Brejinho das Ametistas (BA) que passa por um tratamento de irradiação gama e por dois tratamentos térmicos. Um resultado de coloração alaranjado característico de citrino foi obtido se mostrando condizente com os estudos de FTIR realizados previamente na amostra de ametista.

\subsection{Centro de cor no quartzo}

O quartzo em sua unidade estrutural básica se apresenta como $\mathrm{SiO}_{4}$, estruturado de forma que cada átomo de silício esteja ligado a quatro átomos de oxigênio, estando esses localizados em cada vértice do tetraedro. Entre os tetraedros vizinhos os oxigênios são compartilhados e formam a rede cristalina tridimensional. Comumente, impurezas na forma de íons estão presentes no quartzo substituindo o silício por $\mathrm{Al}^{3+}$ e Fe. Segundo Rossman (1994), tal substituição causa um desequilíbrio eletrônico, por esses cátions possuírem valência 3+, diferentemente do Si que possui valência 4+. Tal desequilíbrio faz com que compensadores eletrônicos ou íons alcalinos como $\mathrm{Li}^{+}, \mathrm{Na}^{+}, \mathrm{K}^{+}$e $\mathrm{H}^{+}$, se instalem na vizinhança dos tetraedros na busca de um rápido restabelecimento do equilíbrio.

De acordo com Pinto et al (2011), o mecanismo de coloração no quartzo tem sido associado à presença de íons na sua estrutura do quartzo. Segundo Lameiras et al (2006) o alumínio é uma impureza muito comum no quartzo. Ele ocorre em teores relativamente baixos, por exemplo, entre 80 e 100 ppm. 


\subsection{Tratamento térmico}

De acordo com Favacho, Liccardo e Castañeda (2001) o tratamento térmico é um beneficiamento capaz de provocar alterações em uma gema por meio de aplicação de calor sob condições adequadas. São determinantes nos resultados e alterações para cada tipo de gema fatores como: a temperatura máxima a ser atingida; o tempo de duração em que a temperatura máxima é mantida; a taxa de aquecimento e resfriamento da temperatura do forno; a natureza química e a pressão atmosférica; assim como a natureza do material em contato com a gema.

Em casos de gemas com inclusões deve ser feita uma avaliação prévia segundo Liz (2008), pois as inclusões podem apresentar coeficientes de dilatação diferentes da própria gema. Ao serem submetidas a temperaturas superiores às da sua formação estas inclusões geram uma zona de alta pressão/tensão ao seu redor podendo levar à fratura da gema. $O$ tratamento térmico pode contribuir para um diagnostico dessas fraturas.

As técnicas podem se utilizar de aquecimento de gemas em tubos de ensaio ou aquecimento em sofisticados fornos elétricos ou a gás com controle de temperatura, pressão e atmosfera. Quanto às temperaturas utilizadas no tratamento térmico, segundo Liz (2008), elas dependem dos objetivos a serem atingidos e da natureza do material a ser tratado, mas variam entre $150^{\circ} \mathrm{C}$ e $1900^{\circ} \mathrm{C}$ para os diversos tipos de tratamentos térmicos de interesse prático.

\subsection{Tratamento por irradiação gama}

O processo de coloração que a radiação natural provoca sobre uma gema consumindo cerca de milhões de anos pode ser realizado em algumas horas com irradiação artificial. Com relação ao mecanismo de ação dos raios gama os feixes de elétrons produzidos pelos aceleradores industriais transferem energia durante a interação com os elétrons das órbitas dos átomos que constituem o objeto irradiado. De acordo com Calvo (2005), as tecnologias de processamento de materiais por raios gama e feixes de elétrons estão consolidadas. No mundo existem mais de 160 irradiadores gama industriais e 1.300 aceleradores industriais de elétrons em operação.

As principais aplicações industriais de radiação, de acordo com IAEA (2008) são a esterilização de produtos de saúde, incluindo farmacêuticos, irradiação de alimentos e produtos agrícolas, materiais de modificação como a polimerização e a coloração de pedras preciosas.

\subsection{Características dos citrinos}

Os citrinos naturais, de grande ocorrência em Minas Gerais, podem variar do amarelo a laranja e chegar até os tons laranja-amarronzados, mas de acordo com Machmeyer e Lehmann (1983), grande parte dos citrinos disponíveis é tratada com irradiação gama. De acordo com Pinto et al (2011), normalmente o citrino é obtido pelo tratamento térmico da ametista a temperaturas de cerca de $500^{\circ} \mathrm{C}$, um processo geralmente irreversível. Segundo Schmetzer (1989), citrinos podem resultar tanto de ametistas do Rio Grande do Sul e Pará, quanto de quartzos fumê submetidos ao tratamento térmico. No caso das ametistas, ao serem submetidas a $470^{\circ} \mathrm{C}$, tornam-se amarelo-clara, e à temperatura de $550-560^{\circ} \mathrm{C}$ tornam-se amarela escura a pardaavermelhada, enquanto que os quartzos fumê resultam em citrinos a $300-400^{\circ} \mathrm{C}$. 
Lehmann e Moore (1966a) relataram que a concentração intersticial de $\mathrm{Fe}^{3+}$ relacionados com defeitos durante o tratamento térmico transforma ametista em citrino. A cor do citrino está associada à precipitação de partículas de ferro na rede de quartzo.

\section{ESTUDO EXPERIMENTAL}

Para a realização deste teste uma amostra de ametista da região de Brejinho das Ametistas (BA) pesando 68,0 gramas foi escolhida por apresentar zonas de cor violeta intensa. A amostra passou por martelação e corte em fatias menores, realizado em equipamento com serra diamantada da marca Lapidart.

Os testes de irradiação foram realizados por meio de ensaios de irradiação gama, utilizando irradiador Panorâmico Múltipropósito de Categoria II, fabricado pela MDS Nordion no Canadá, Modelo/número de série IR-214 e tipo GB-127, equipado com uma fonte de Cobalto-60 estocada a seco com atividade máxima de $2.200 \mathrm{TBq}$ ou $60.000 \mathrm{Ci}$. Este aparelho está no Laboratório de irradiação Gama (LIG) do Centro de Desenvolvimento da Tecnologia Nuclear - CDTN-CNEN/MG. As amostras foram embaladas em papel alumínio, envolto em fita adesiva com a identificação da dose a ser aplicada em kGy ficando o tempo de exposição a cargo do operador técnico responsável pelo laboratório.

O tratamento térmico das pedras foi realizado no laboratório do CDTN utilizando forno tipo mufla e termopar da marca Minipa para medição da temperatura. A temperatura desejada foi atingida de forma lenta e gradual para que não ocorressem fraturas nas amostras.

Os testes de FTIR foram realizados no Laboratório de Espectrometria na Região do Infravermelho e Ultravioleta e Visível (LABESPEC) do Centro de Desenvolvimento da Tecnologia Nuclear (CDTN/BH). O aparelho utilizado nos ensaios foi um Bomem, modelo MB 102.

Foram utilizados fragmentos de ametista medindo de 3 a $8 \mathrm{~mm}$ de espessura, os quais foram obtidos por meio de martelação. De acordo com Drummond (2010), o ensaio de FTIR é uma boa ferramenta para a detecção e sinalização de possíveis mudanças de cor que um cristal hialino irá apresentar ao ser irradiado com raios gama e subsequentemente aquecido.

A amostra escolhida para este teste foi pode ser vista na Figura 1, que mostra a coloração violeta-escura em algumas partes.

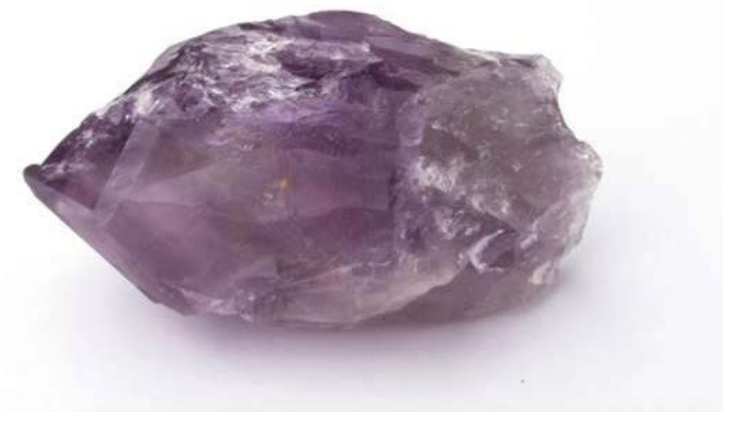

Figura 1: Ametista de Brejinho das Ametistas (BA)

Fonte: Elaborado pelos autores com base na pesquisa realizada 


\subsection{Identificação do potencial de coloração na amostra}

É importante que uma identificação do potencial de coloração seja feita por meio do uso da espectroscopia na região do infravermelho que irá identificar elementos dopantes presentes nas amostras. A identificação do potencial de coloração feita através de testes de irradiação e aquecimento em amostras representativas enviadas para irradiadores torna-se um procedimento demorado, que não atende a necessidade do mercado de pedras semipreciosas (LAMEIRAS et al, 2006).

Foi realizado ensaio de FTIR que mostra na Figura 2 os espectros obtidos cujos $\mathrm{fa}=3,03$ e banda intensa em $3576 \mathrm{~cm}^{-1}$ apontam resultados para ametista.

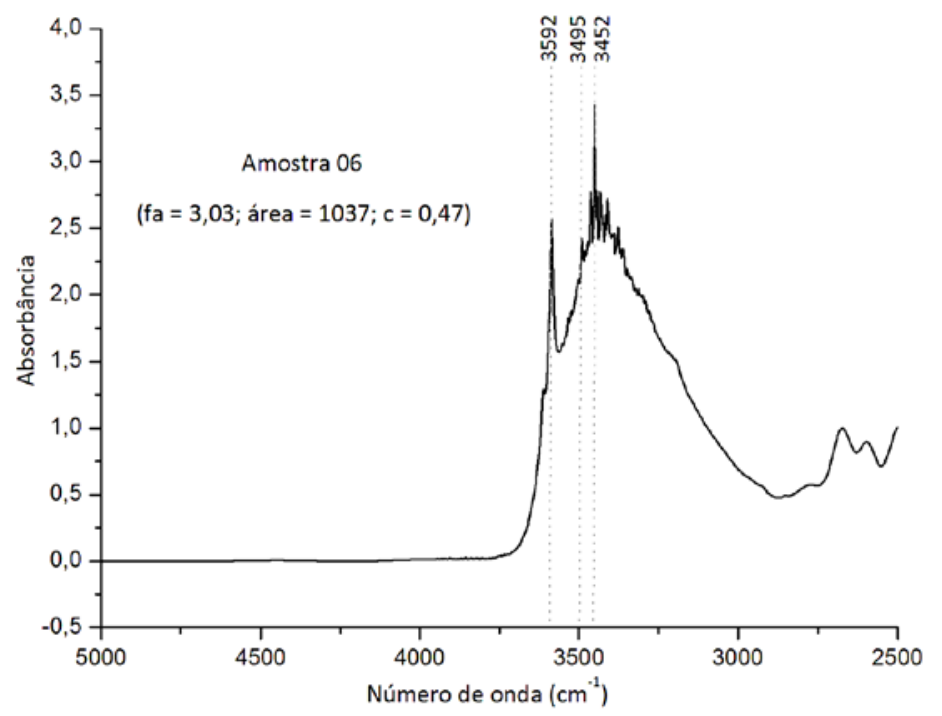

Figura 2: FTIR ametista de Brejinho das Ametistas (BA)

Fonte: Elaborado pelos autores com base na pesquisa realizada

Segundo Schmetzer (1989), assim como na ametista, a cor do citrino tratado termicamente está associada à impureza do ferro, mas no estado de oxidação $\mathrm{Fe}^{3+}$, embora o assunto da cor seja ainda polêmico por ser aceita a influência da irradiação e de outras causas desconhecidas. Para o citrino natural Barry e Moore (1964), também indicaram o íon $\mathrm{Fe}^{3+}$ substitucional como causa mais provável de cor.

\subsection{Tratamento térmico e irradiação gama}

A amostra foi submetida ao tratamento térmico com o objetivo de obter como resultado um aspecto leitoso, passando por uma sequência de etapas de aquecimento térmico a $500^{\circ} \mathrm{C}$ por 6 horas sendo observada em intervalos de tempo para averiguar a perda da cor e a obtenção do resultado esperado. Como pode ser visto na Figura 3 (b) a amostra fraturou gerando pequenos pedaços nos quais a cor violeta fraca era prevalente. Uma das partes foi selecionada para novo aquecimento como pode ser visto em (c). Ao ser submetida à temperatura de $600^{\circ} \mathrm{C}$ por 2 horas essa amostra mudou sua cor para alaranjado característica de citrino. 


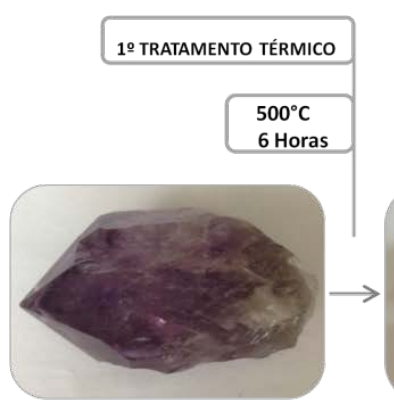

(a)

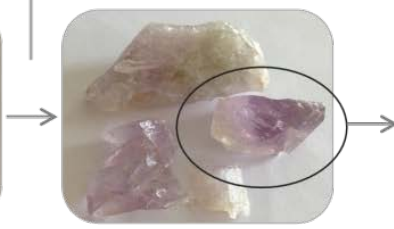

(b)

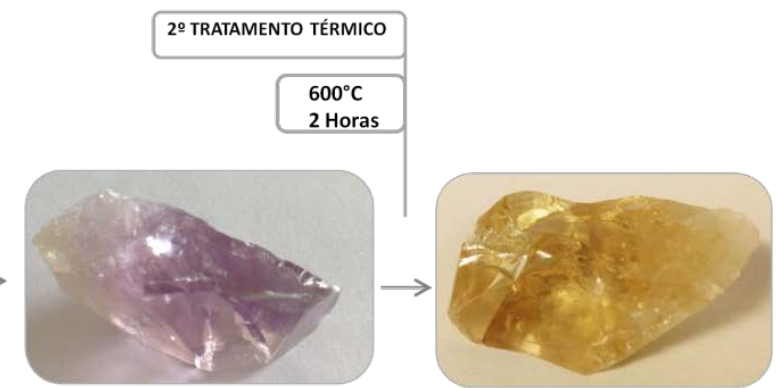

(c)

(d)

Figura 3: Sequência de etapas de beneficiamento

Fonte: Elaborado pelos autores com base na pesquisa realizada

Os resultados convergem para o que argumentam Trindade e Escalvi (2006) de que algumas variedades de ametistas quando aquecidas a $500^{\circ} \mathrm{C}$ adquirem tonalidades de cor que varia do amarelo-claro ao amarelo-alaranjado. Dependendo da localização e ambiente de origem da ametista a cor após o aquecimento pode ser amarelo no caso do citrino. Para Nassau (1978), mesmo que a cor amarela após o aquecimento seja uma transição em metal cor de impureza, a própria cor da ametista deriva de um centro de cor. Um tratamento por irradiação após o aquecimento pode recriar centro da cor e retomar a cor de ametista. Lehmann e Moore (1966b) detalham que a ametista natural e o citrino contêm centros que parecem consistir de $\mathrm{Fe}^{3+}$ substituído no lugar do $\mathrm{Si}^{4+}$ com um íon álcali-metálico de carga neutralizante na área intersticial adjacente situada no eixo duplo do tetraedro de oxigênio. Chamam esse centro de $S_{1}$. Um segundo centro anteriormente atribuído ao $\mathrm{Fe}^{3+}$ veio a ser atribuído mais tarde ao $\mathrm{Fe}^{3+}$ no sitio intersticial, o qual foi denominado de centro I.

\section{APLICAÇÃO DO MATERIAL NO DESIGN DE JOIAS}

O aspecto físico do material se associa à história do produto, do território e da comunidade que o produz. Em se tratando das gemas, a sua origem e procedência são informações que despertam no consumidor o anseio de valorizar determinado local, território ou país. Segundo Teixeira (2001), independente de fatores como durabilidade, valor intrínseco ou dos significados simbólicos atribuídos às gemas, elas podem conferir ao produto final um caráter exótico, além de refletir o contexto de onde são concebidos. As gemas brasileiras ao serem aplicadas nas joias, além de um significado simbólico intrínseco, possuem também o papel de comunicar a origem do material que compõe a joia. Os aspectos subjetivos do material neste estudo se referem à coloração, podendo ser de acordo com Dias (2009), aqueles que provocam as emoções estéticas, podendo ser traduzidos pela cor, forma, transparência, brilho, tato, som, cheiro, sabor, temperatura, propriedades físicas e mecânicas, e expressas pelo processo de fabricação.

Uma atuação de forma sistêmica tem motivado alguns setores da indústria brasileira almejando agregar valor a seus produtos que gerem maior competitividade, tanto no mercado interno, quanto externo. Para isso acontecer, a indústria teve que adotar uma percepção mais concisa em relação ao design, ao desenho diferenciado (ROCHA e ROCHA, 2014). Diante da abertura do mercado brasileiro às importações na década de 90 , surge a inevitável comparação por parte do consumidor, forçando a 
joalheria nacional a buscar conhecimento e qualificação. $O$ mercado requer profissionais que utilizem os conhecimentos gerais, culturais, as tendências de mercado, sem, contudo, esquecer-se das questões éticas e ambientais (GOLA, 2008).

Os concursos de joias internacionais que surgiram a partir do final dos anos 80 tiveram grande participação de brasileiros com expressiva classificação como finalistas em joias que representavam a 'brasilidade'. Mas foi em 1990 com a criação do 10 Prêmio IBGM de Design, que houve uma diferenciação do design de joias brasileiro no mercado internacional. O prêmio é um poderoso instrumento de incentivo e avaliação de novos talentos abrindo oportunidades para a valorização do profissional (GOLA, 2008).

A Figura 4 mostra uma peça projetada por um dos autores com aplicação de citrino obtido por beneficiamento de tratamento de irradiação gama e aquecimento. A gema recebeu lapidação em forma de gota com facetamento negativo simulando bolhas em ebulição.

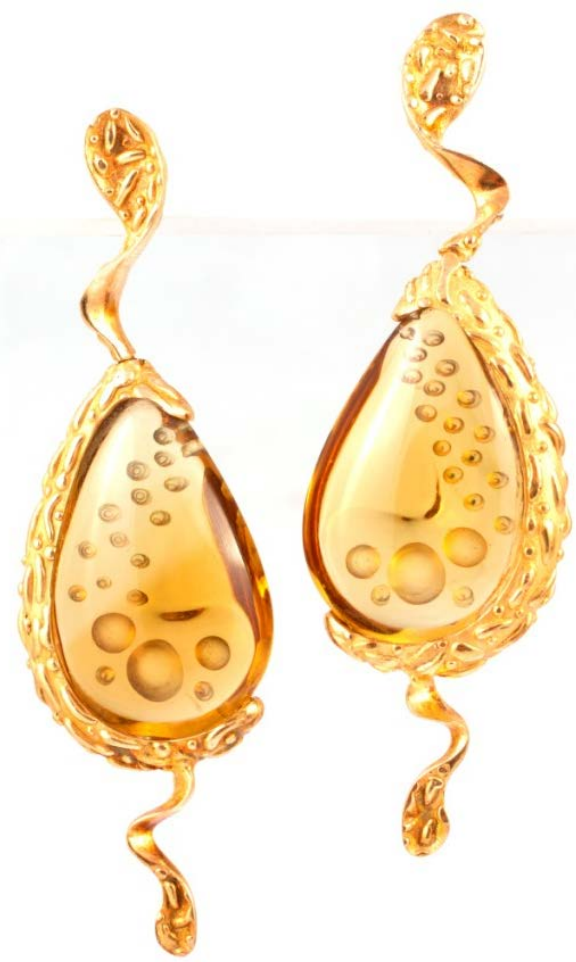

Figura 4: Brinco Classificado no Prêmio SEBRAE 2014

Fonte: Elaborado por um dos autores

\section{CONCLUSÃO}

A atuação de forma sistêmica na cadeia de valor envolve uma maior preocupação para o uso da matéria-prima, seja no uso de forma sustentável ou beneficiando-a como forma de agregação de valor. No que tange o uso dos recursos naturais, talvez o desafio adicional que impera no cenário atual seja o design aliar a tecnologia como forma de beneficiamento da matéria-prima pouco valorizada com o objetivo de aumentar seu valor percebido pelo usuário.

As limitações nesta pesquisa dizem respeito à dificuldade de encontrar amostras com potencial de coloração adequado para os testes e resultados esperados, além de mostrar pouca disposição dos fornecedores de pedras em compartilhar 
informações que poderiam vir a contribuir com a academia. Tal fato corrobora com resultados levantados por ações governamentais junto às cooperativas do setor de base mineral que mostram que um dos entraves ao seu crescimento diz respeito à desunião dos cooperados.

Para trabalhos futuros, a conclusão da pesquisa de mestrado em fase final, se pretende compilar testes e aplicações do quartzo na joalheria em formato de um catálogo físico e virtual para divulgação dos resultados vistos e alcançados, que possam contribuir com o setor joalheiro, mostrando os caminhos para tornar o design de joias brasileiro mais competitivo.

\section{REFERÊNCIAS}

BARRY, T. I.; MOORE, W. J. Amethyst: optical properties and paramagnetic resonance. Science. n. 144, pp. 289-290, 1964.

CALVO,W.A.P. Desenvolvimento do sistema de irradiação em um irradiador multipropósito de cobalto-60 tipo compacto. 2005, 178 f. Tese (Doutorado em Ciências na área de Tecnologia Nuclear)-IPEN, Universidade de São Paulo, USP. São Paulo, 2005.

DIAS, M.R.A.C. Percepção dos materiais pelos usuários: modelo de avaliação Permatus. 2009. 352 f. Tese (Doutorado em Engenharia e Gestão do Conhecimento)Universidade Federal de Santa Catarina, UFSC, Florianópolis, 2009.

DRUMMOND, N.F; MENDES, J.C.; LAMEIRAS, F.S. Caracterização de quartzo para obtenção de suas variedades gemológicas por irradiação gama e/ou tratamento térmico, Revista Escola de Minas, v. 3, n. 63, 2010, pp. 449-456.

FAVACHO, S. M.D, LICCARDO, A.; CASTAÑEDA, C. Tratamento em gemas. In: CASTAÑEDA, C.; ADDAD, J. E.; LICCARDO, A. Gemas de Minas Gerais. Belo Horizonte: Ed. SBG, 2001. cap. 3, pp. 53-73.

FAVACHO, S. M.D. Quartzo; In: CASTAÑEDA, C.; ADDAD, J. E.; LICCARDO, A. Gemas de Minas gerais. Belo Horizonte: Ed. SBG, 2001. cap. 10, pp. 221-233.

GOLA, E. A joia: história e design. São Paulo: SENAC/SP, 2008.

IAEA - International Atomic Energy Agency. Gamma irradiators for radiations processing. Viena: 2008. Disponível em < http://www-

naweb.iaea.org/napc/iachem/Brochure\% >. Acesso em: 22 de maio de 2015.

KRUCKEN, L. Design e território: valorização de identidades e produtos locais. São Paulo: Studio Nobel, 2009.

LAMEIRAS, F.S; NUNES, E. H. M.; MELO, V.A.R.; LIZ, O.R. Identificação de quartzos incolores para joalheria, Revista Escola de Minas, v. 59, n. 1, pp. 129-133, 2006.

LEHMANN, G,; MOORE, W.J. Color center in amethyst quartz. Science, v. 152, pp. 1061-1062, 1966a.

LEHMANN. G.; MOORE, W. J. Optical and paramagnetic properties of iron centers in quartz. Journal of Chemical Physics, v. 44, n. 5, 1966b. 
LIZ, O.S.R. Técnicas para o tratamento de gemas. Belo Horizonte: CETEC, 2008.

Disponivel em <www.sbrt.ibict.br/dossie-tecnico/downloadsDT/Mjl4 >. Acesso em: 21 de agosto de 2015.

MACHMEYER D.; LEHMANN G. A trapped-hole center causing rose coloration of natural quartz. Zeitschrift für kristallographie, n. 163, p. 181-196, 1983.

NASSAU, K. The origins of color in minerals. American mineralogist.Murray Hill, New Jersey. V. 63, p. 219-229, 1978.

PINTO,L. C. B. de M.;RIGHI, A.; LAMEIRAS, S.L.; ARAUJO, G.S.A.; KRAMBROCK, K. Origin of the color in cobalt-doped quartz, Phys Chem Minerals, v. 38, p. 623-629, 2011.

ROCHA, S.C.S; ROCHA, P.R. O Brasil da joia, design e arte.São Paulo: Ed. Do autor, 2014.

ROSSMAN, G.R. Colored varieties of the silica minerals, Review in Mineralogy, v. 29, pp. 433-467, 1994.

SCHMETZER, K.; Methods for the distinction of natural and synthetic citrine and prasiolite, Journal of Gemmology, v. 23, n. 5, 1989, pp. 288-293.

TEIXEIRA, M.B.S. Design de joias em Minas Gerais. A construção de uma identidade. In: CASTAÑEDA, Cristiane; ADDAD, J. E; LICCARDO, Antonio. Gemas de Minas Gerais. Belo Horizonte: Ed. SBG, 2001, cap. 10, pp. 261-280.

TRINDADE, N. M.; SCALVI, R. M. F. Análise das propriedades ópticas de ametistas tratadas termicamente. In: Anais do 170 Congresso brasileiro de Engenharia e ciências dos Materiais, 2006, Foz do Iguaçu. 